Discussion Paper No. 718

\title{
QUOTAS UNDER DYNAMIC \\ BERTRAND COMPETITION
}

\author{
Kaz Miyagiwa \\ and \\ Yuka Ohno
}

August 2008

The Institute of Social and Economic Research

Osaka University

6-1 Mihogaoka, Ibaraki, Osaka 567-0047, Japan 


\title{
Quotas under dynamic Bertrand competition
}

\author{
Kaz Miyagiwa* \\ Osaka University and Emory University \\ and \\ Yuka Ohno \\ Deloitte Tax LLP
}

\begin{abstract}
$\underline{\text { Abstract }}$
We present a new model of dynamic Bertrand competition, where a quota is treated as an intertemporal constraint rather than as a capacity constraint as is common in the literature. The firm under a quota then can still vary the rates of exports over time provided that its total sales within the period do not exceed the quota. We show that a quota results in higher prices than a tariff of equal imports. We also show that firms never play mixed strategies, which contrasts from the result from a one-shot game, in which the only equilibrium under a quota is in mixed strategies.
\end{abstract}

JEL Code: F13

Keywords: Dynamic Bertrand competition, quotas, tariffs, differential game

\footnotetext{
* Corresponding author. The Institute of Social and Economic Research, Osaka University, 6-1 Mihogaoka, Ibaraki, Osaka 567-0047, Japan. E-mail: kmiyagiwa@gmail.com. We thank participants at the Hitotsubashi COE/RES Conference on International Trade and FDI, and Economics Department seminars at the University of Texas-Arlington and Osaka University for comments and suggestions. We alone are responsible for any errors.
} 


\section{Introduction}

This paper presents a new model of dynamic Bertrand competition under a quota. The model reflects the idea that an exporter facing a quota behaves quite differently from a firm facing a capacity constraint. A quota specifies how much a firm is allowed to export within a given period, say, one year. A firm under the quota can still vary the rates of export over the course of the year as long as its annual total exports do not exceed the quota. In contrast, a capacity-constrained firm is subject to the production limit per unit of time, say, due to the plant size, and therefore does not face a dynamic constraint like a firm under the quota. This distinction between a quota and a capacity constraint is lost in the literature, however. Virtually every dynamic model of oligopoly examining the effect of quotas, no doubt influenced by the capacity constraint literature (e.g., Kreps and Sheinkman, 1983), treats a quota as a capacity constraint.

The objective of the present paper is therefore to explore the nature of a quota as a dynamic quantity constraint. To that end we consider Bertrand (price-setting) competition between a foreign firm and a domestic firm in the domestic market during a given period. Firms produce differentiated goods and choose prices continuously over time during to maximize total profits within the period. In addition, the foreign firm is subject to a quota during that period. We solve this model for a subgame-perfect equilibrium.

Our analysis makes two main contributions to the literature. A first is to the literature on the relative effect of tariffs and quotas. It is well know that tariffs and quotas are equivalent under perfect competition in the sense that replacement of a tariff with an equal-import quota leaves the domestic price intact. Over the last quarter-century the validity of this proposition has been questioned under various forms of market structure. ${ }^{1}$ In static settings Itoh and Ono (1982, 1984), Harris (1985), and Krishna (1989) showed for

\footnotetext{
${ }^{1}$ See, e.g., Helpman and Krugman (1989) and Brander (1995) for surveys of early work.
} 
Bertrand duopoly that the quota results in a higher domestic price than the tariff while Hwang and Mai (1988) reaffirmed the equivalence of the two policy instruments for Cuournot duopoly.

The relative effect of tariffs and quotas has also been examined in dynamic contexts. Rotemberg and Saloner (1989) analyzed a collusive equilibrium in a repeated-game setting and found that a quota results in a lower domestic price than a tariff of equal imports. The reason for this surprising result is that under the quota the foreign firm is prevented from punishing the home firm as harshly as under the tariff when the latter cheats. Hence, the equilibrium price must be set lower to curb the home firm's temptation to cheat and to restore collusion. Dockner and Haug (1990) considered a dynamic Cournot model with slow price adjustment, and showed that a quota results in higher prices than the quota as the price adjust to the equilibrium. However, why the market remains out of equilibrium is not explained. Miyagiwa and Ohno $(1995,1999)$ re-examined the infant-industry argument for protection, showing that a quota generally delays adoption or innovation of new technology relative to a tariff. All these authors assumed the quota binding at each point in time, thereby ignoring the possibility of intra-period variations in prices, which is the focus of this paper. An exception is the work of Miyagiwa and Ohno (2001). Treating quotas as dynamic constraints and examining the intra-period variations in prices and output for Cournot duopoly, they found that the equilibrium price is higher under the quota, showing that the static result of Hwang and Mai (1988) does not extend to a dynamic setting.

A second contribution this paper makes to the literature concerns the fact that models of oligopoly under a quota may not possess equilibria in pure strategies. A basic reference is Krishna (1989), who showed that for differentiated Bertrand competition the only Nash equilibrium under the quota is in mixed strategies. In repeated-game setting, Rotemberg and Saloner (1989) also showed that the stage game has homogeneous-goods 
Bertrand firms playing mixed strategies in equilibrium. The absence of pure-strategy equilibrium under quotas is not unique to Bertrand competition, however. Reitzes and Grawe (1994) showed that Cournot duopoly has the unique mixed-strategy equilibrium under market-share quotas, i.e., when the foreign firm is constrained not to exceed the prescribed fraction of sales in the domestic market.

The logic underling these results cannot be faulted. Some researchers have nonetheless expressed skepticism about mixed-strategy equilibriums. The following statement by Brander (1995, p. 1436) summarizes this sentiment: "The value of Krishna is not so much that it is likely to be a literal description of an actual outcome. The paper's contribution is that it focuses attention on the idea that a VER (and, by extension, any trade policy instrument) can have important effects through the effects on imperfectly competitive rivalries between firms." Our model throws light on this issue. The above-mentioned models possess no pure-strategy Nash equilibrium under the quota because the game is static (Krishna 1989, Reitzes and Grawe 1994) or equivalently a quota is binding at every instant (Rotemberg and Saloner 1989). Using Krishna (1989)'s model as a benchmark, we show that, when a quota serves as a dynamic constraint, firms never play mixed strategies.

The next section reviews the Krishna model, which serves as a benchmark. Section 3 sets out the dynamic Bertrand model, showing the absence of mixed strategy equilibrium under a quota. Section 4 presents additional properties of the equilibrium, and shows that normally a quota leads to higher price trajectories than the equal-import tariff. Section 5 reconsiders the facilitating nature of quotas. Concluding remarks are in the final section.

\section{The one-shot price-setting game under the quota}

This section provides a brief review of the Krishna (1989) model, pointing out its essential features that will be useful in the next section. The Krishna model is an application 
of the standard differentiated-goods Bertrand duopoly model, where a domestic and a foreign firm play a one-shot price-setting game in the domestic market. Let $\mathrm{P}$ and $\mathrm{p}$ denote the prices of the domestic and the foreign good, respectively. (Notationally, we use capital letters to denote the domestic firm and lower case to denote the foreign firm.) Write the demand function for the domestic and the foreign $\operatorname{good}$ as $\mathrm{X}(\mathrm{P}, \mathrm{p})$ and $\mathrm{x}(\mathrm{P}, \mathrm{p})$, respectively. Assume that demands are downward sloping $\left(\mathrm{X}_{\mathrm{P}}<0\right.$ and $\left.\mathrm{x}_{\mathrm{p}}<0\right)$, and goods are substitutes $\left(X_{p}>0\right.$ and $\left.x_{P}>0\right)$, where the subscripts denote partial derivatives.

Suppose that free trade prevails. The foreign firm takes $\mathrm{P}$ as given and chooses $\mathrm{p}$ to maximize the profit:

$$
\mathrm{v}(\mathrm{P}, \mathrm{p}) \equiv \mathrm{px}(\mathrm{P}, \mathrm{p})-\mathrm{c}(\mathrm{x}(\mathrm{P}, \mathrm{p}))
$$

where $\mathrm{c}($.) is the foreign firm's cost function, with c' $>0$ and $c " \geq 0$ (primes denote derivatives). The domestic firm takes $\mathrm{p}$ as given and chooses $\mathrm{P}$ to maximize the profit:

$$
\mathrm{V}(\mathrm{P}, \mathrm{p}) \equiv \mathrm{PX}(\mathrm{P}, \mathrm{p})-\mathrm{C}(\mathrm{X}(\mathrm{P}, \mathrm{p}))
$$

where $\mathrm{C}($.$) is the domestic firm's cost function, with \mathrm{C}^{\prime}>0$ and $\mathrm{C}^{\prime \prime} \geq 0$. The first-order condition:

$$
\mathrm{v}_{\mathrm{p}}(\mathrm{P}, \mathrm{p})=\mathrm{x}(\mathrm{P}, \mathrm{p})+\mathrm{px}_{\mathrm{p}}(\mathrm{P}, \mathrm{p})-\mathrm{c}^{\prime}[\mathrm{x}(\mathrm{P}, \mathrm{p})] \mathrm{x}_{\mathrm{p}}(\mathrm{P}, \mathrm{p})=0
$$

implicitly defines the foreign firm's best-response function, $p=b^{\mathrm{s}}(\mathrm{P})$. The domestic firm's best-response function, $\mathrm{P}=\mathrm{B}^{\mathrm{S}}(\mathrm{p})$, obtains analogously from the first-order condition:

$$
\mathrm{V}_{\mathrm{P}}(\mathrm{P}, \mathrm{p})=\mathrm{X}(\mathrm{P}, \mathrm{p})+\mathrm{PX}_{\mathrm{P}}(\mathrm{P}, \mathrm{p})-\mathrm{C}^{\prime}[\mathrm{X}(\mathrm{P}, \mathrm{p})] \mathrm{X}_{\mathrm{P}}(\mathrm{P}, \mathrm{p})=0 .
$$

Assume that $\mathrm{v}(\mathrm{P}, \mathrm{p})$ is strictly concave in $\mathrm{p}$ and $\mathrm{V}(\mathrm{P}, \mathrm{p})$ is strictly concave in $\mathrm{P}$ so that the best-response functions are indeed "functions".

Solving the two best-response functions simultaneously yields the one-shot Nash equilibrium denoted by $\left(\mathrm{P}^{\mathrm{s}}, \mathrm{p}^{\mathrm{s}}\right)$. (We call this the "static" Nash equilibrium later and use 
the superscript $\mathrm{s}$ to denote it). The best-response functions and the Nash equilibrium $\left(\mathrm{P}^{\mathrm{S}}\right.$, $p^{s}$ ) under free trade are shown in Figure 1. The best-response functions slope upward since prices are strategic complements as is usually assumed. The intersection point $\mathrm{S}$ of the two best-response functions corresponds to the Nash equilibrium. The usual conditions are invoked to ensure the uniqueness of the equilibrium. ${ }^{2}$ The equilibrium outputs and profits obtain by substituting $\mathrm{P}^{\mathrm{s}}$ and $\mathrm{p}^{\mathrm{s}}$ into each firm's demand and objective functions. Let $\mathrm{X}^{\mathrm{s}} \equiv$ $\mathrm{X}\left(\mathrm{P}^{\mathrm{s}}, \mathrm{p}^{\mathrm{s}}\right)$ and $\mathrm{x}^{\mathrm{s}} \equiv \mathrm{x}\left(\mathrm{P}^{\mathrm{s}}, \mathrm{p}^{\mathrm{s}}\right)$ denote, respectively, the domestic and the foreign firm's static equilibrium output.

Suppose now that there is a quota set at $\tilde{\mathrm{q}}=\mathrm{x}^{\mathrm{s}}$, the equilibrium quantity of imports under free trade. The effect is seen in Figure $1 .^{3}$ The curve qq* represents the locus of $\mathrm{P}$ and $\mathrm{p}$ such that the demand for the foreign product just satisfies the quota; that is, $\widetilde{\mathrm{q}}=\mathrm{x}(\mathrm{P}$, p). By design it necessarily goes though S. Given P, if the foreign firm charges a price less than the price that satisfies this equation, the demand for the foreign product exceeds the quota. This shortage for the foreign good is assumed to vanish through consumer arbitrage. That is, those consumers lucky enough to get the foreign good at a lower price resell their purchased units at the market-clearing price implied by the locus qq*. Therefore, the foreign firm would not have any incentive to set a price below the locus qq*. Hence, its bestresponse function consists of the part of $\mathrm{qq}^{*}$ to the right of the $\mathrm{b}^{\mathrm{s}}$ schedule and the part of $\mathrm{b}^{\mathrm{s}}$ below the locus $\mathrm{qq}^{*}$, as indicated by the thick line with a distinct kink at the point $\mathrm{S}$. The domestic firm's best-response function under the quota (also shown in bold) is not even

\footnotetext{
${ }^{2}{ }_{\mid} \mathrm{vpp}>{ }_{\mid} \mathrm{v}_{\mathrm{pP} \mid}$ and ${ }_{\mid} \mathrm{V}_{\mathrm{PP} \mid}>\mid \mathrm{V}_{\mathrm{Pp} \mid}$ guarantee the equilibrium to be unique and stable.

${ }^{3}$ Figure 1 duplicates Krishna's Figure 3, where the quota is set at the free-trade level of imports.
} 
continuous, consisting of the part of its original best-response curve $\mathrm{B}^{\mathrm{s}}$ to the right of $\hat{\mathrm{p}}$ and the horizontal line at $\mathrm{P}^{\mathrm{H}}$ up to $\hat{\mathrm{p}}$. The horizontal best response function is again due to consumer arbitrage, which raises any price $\mathrm{p}$ set by the foreign firm to the market-clearing price on $\mathrm{qq}^{*}$. Then the home firm best-responds by setting the price equal to $\mathrm{P}^{\mathrm{H}}$, where its iso-profit curve is tangent to qq*. The effect on the domestic firm's demand therefore is exactly what it would be if the foreign firm directly charged $\mathrm{p}^{\mathrm{A}}$ instead of $\hat{p}$; i.e., the demand for the domestic good is given by $\mathrm{X}\left(\mathrm{P}^{\mathrm{H}}, \mathrm{p}^{\mathrm{A}}\right)$. This holds true whenever $\mathrm{p}$ is below (to the left of) qq*. When the foreign firm sets $\hat{p}$, however, the home firm can earn the same profit by responding with price $\mathrm{P}^{\mathrm{L}}$ or $\mathrm{P}^{\mathrm{H}}$ as shown in the figure. For any price higher than $\hat{\mathrm{p}}$, the home firm's best responses are indicated by the best-response function $\mathrm{B}^{\mathrm{S}}(\mathrm{p})$.

Since the two best-response functions do not intersect each other, there is no Nash equilibrium in pure strategies. However, there is a unique Nash equilibrium in which the domestic firm randomizes between $\mathrm{P}^{\mathrm{H}}$ and $\mathrm{P}^{\mathrm{L}}$ and the foreign firm charges $\hat{\mathrm{p}}$. Since both $\mathrm{P}^{\mathrm{H}}$ and $\mathrm{P}^{\mathrm{L}}$ are higher than $\mathrm{P}^{\mathrm{s}}$, and $\hat{\mathrm{p}}$ is higher than $\mathrm{p}^{\mathrm{s}}$, we conclude that the quota raises prices of both firms. This conclusion holds even when the quota is set equal to the volume of imports under the existing tariff. That is, the quota raises prices of both the foreign and the domestic firm relative to the tariff.

Notice that, since the domestic firm randomizes between $\mathrm{P}^{\mathrm{H}}$ and $\mathrm{P}^{\mathrm{L}}$, its profit from each action must be identical, as indicated by the iso-profit curve. Thus, the domestic firm earns a greater profit under the quota. The foreign firm exports the same quantity under the quota as under free trade but its price is higher now. Therefore, the foreign firm also benefits from the quota (as long as the quota is not too restrictive). 


\section{The quota as a dynamic constraint}

\subsection{Setup}

We now consider the model of differentiated-goods Bertrand duopoly in a infinitetime setting, where time $\mathrm{t}$ flows continuously from zero to infinity. Divide the time set $[0$, $\infty)$ into infinitely many non-overlapping unit intervals called years, that is,

$$
[0, \infty)=[0,1) \cup[1,2) \cup[2,3) \cup \ldots
$$

$\mathrm{X}(\mathrm{P}(\mathrm{t}), \mathrm{p}(\mathrm{t}))$ and $\mathrm{x}(\mathrm{P}(\mathrm{t}), \mathrm{p}(\mathrm{t}))$ now denote instantaneous demand functions at time $\mathrm{t}$. The demand functions are stationary over time. Finite reservation prices exist and quantities demanded are finite for all (p, P). The Markov-perfect equilibrium is used as the solution concept to preserve the properties of the one-shot game.

Under free trade, firms choose prices simultaneously at each instant t to maximize profits over an infinite time horizon. Since there are no "state variables", the model is stationary in the sense that subgames starting at any $t \in[0, \infty)$ are identical. Therefore, the equilibrium outcome at any $t$ is exactly the same as that in the one-shot Bertrand game. That is, in the Markov-perfect equilibrium the foreign firm produces $x^{s}$ units and charges $p^{s}$ while the domestic firm produces $X^{S}$ units and sells them at $\mathrm{p}^{\mathrm{s}}$ at each $\mathrm{t} \in[0, \infty)$.

\subsection{Quotas}

Suppose that the foreign firm is subject to an annual quota $\overline{\mathrm{q}}$. Since a year is a unit interval, we can write the constraint facing the foreign firm as:

$$
\int_{\tau}^{\tau+1} x(P(t), p(t)) d t \leq \bar{q},
$$


for all $\tau=0,1,2, \ldots$. To make the analysis interesting, we assume that the quota is binding, that is, $\overline{\mathrm{q}}$ is less than the total volume of exports under free trade:

$$
\overline{\mathrm{q}} \leq \int_{\tau}^{\tau+1} \mathrm{x}^{\mathrm{s}} \mathrm{dt} .
$$

The constraint (3) implies that how much more output the foreign firm can export during the remainder of a given year depends on the total output it has sold to date in that year. Thus, the past sales become a "state variable" in the dynamic optimization problem facing the foreign firm. However, the foreign firm cannot usually carry the unused portion of the quota over to the following years. Then, by the property of Markov-perfect equilibrium, whatever happens during the year has no effect on the subgames beginning in the following or later years. This fact lets us focus on the first year; i.e., $t \in[0,1)$.

Since we are interested in the subgame perfect equilibrium we solve the model backward, using dynamic programming techniques. Suppose we are at a given time $\mathrm{z} \in[0$, 1). Let $\mu(\mathrm{z})$ denote the foreign firm's total output up to a time $\mathrm{z}<1$, that is:

$$
\mu(\mathrm{z}) \equiv \int_{0}^{\mathrm{z}} \mathrm{x}(\mathrm{P}(\mathrm{t}), \mathrm{p}(\mathrm{t})) \mathrm{dt} .
$$

Then, the maximum quantity the foreign firm is allowed to sell in the interval $[\mathrm{z}, 1)$ is equal to $\overline{\mathrm{q}}-\mu(\mathrm{z})$. Thus, the foreign firm's quantitative constraint at time $\mathrm{z}$ is written as:

$$
\int_{z}^{1} x(P(t), p(t)) d t \leq \bar{q}-\mu(z) .
$$


Subject to this isoperimetric constraint, and taking $\mu(\mathrm{z})$ and $\mathrm{P}(\mathrm{z})$ as given, the foreign firm chooses $\mathrm{p}(\mathrm{t})$ for $\mathrm{t} \in[\mathrm{z}, 1)$ to maximize the sum of profits over the interval $[\mathrm{z}, 1)$ :

$$
\int_{z}^{1} e^{-r t}\{p(t) x(P(t), p(t))-c(x(P(t), p(t)))\} d t
$$

where $r$ is the instantaneous rate of interest. The domestic firm faces no quantitative restriction, so it takes $\mathrm{p}(\mathrm{z})$ as given and chooses $\mathrm{P}(\mathrm{t})$ to maximize the following intertemporal profit over $\mathrm{t} \in[\mathrm{z}, 1)$ :

$$
\int_{\mathrm{z}}^{1} \mathrm{e}^{-\mathrm{rt}}\{\mathrm{p}(\mathrm{t}) \mathrm{X}(\mathrm{P}(\mathrm{t}), \mathrm{p}(\mathrm{t}))-\mathrm{C}(\mathrm{X}(\mathrm{P}(\mathrm{t}), \mathrm{p}(\mathrm{t})))\} \mathrm{dt} .
$$

\subsection{Characterization of the equilibrium under the quota}

We first prove the following proposition, which is useful in solving the model.

Proposition 1. Both the firms play pure strategies at each $t \in[0,1)$.

We prove this by contradiction. Suppose that a mixed strategy is played at any time $\mathrm{t}^{0} \in[0$, 1). When the quantitative restriction does not bind, strict concavity of the flow profit functions $\mathrm{V}(\mathrm{p}, \mathrm{p})$ and $\mathrm{v}(\mathrm{P}, \mathrm{p})$ implies that firms play pure strategies. Therefore, for firms to

play mixed strategies at $\mathrm{t}^{0}$, at least one firm must have a non-concave flow profit function. Then the discussion developed in section 2 leads to the following result. 
Result: When the quota binds at $\mathrm{t}^{0}$, at a time $\mathrm{t} \in\left[\mathrm{t}^{0}, \mathrm{t}^{0}+\varepsilon\right]$ where $\varepsilon(>0)$ is arbitrarily small, the domestic firm randomizes between $\overline{\mathrm{P}} \equiv \mathrm{P}^{\mathrm{H}}\left(\mathrm{t}^{0}\right)$ and $\underline{\mathrm{P}} \equiv \mathrm{P}_{\mathrm{L}}\left(\mathrm{t}^{0}\right)$ while the foreign firm charges $\hat{p} \equiv \hat{p}\left(t^{0}\right)$. (Strict concavity of the profit function rules out other types of mixed-strategy equilibria).

Let $\Omega\left(\mathrm{P}, \hat{\mathrm{p}}, \mathrm{t}^{0}\right)$ denote the domestic firm's future profit when it charges the price $\mathrm{P}$ during $\left[\mathrm{t}^{0}, \mathrm{t}^{0}+\varepsilon\right]$. When it randomizes between $\overline{\mathrm{P}}$ and $\mathrm{P}$, the domestic firm's future profits must be identical; that is, $\Omega\left(\overline{\mathrm{P}}, \hat{\mathrm{p}}, \mathrm{t}^{0}\right)=\Omega\left(\underline{\mathrm{P}}, \hat{\mathrm{p}}, \mathrm{t}^{0}\right)$. We show that this is a contradiction.

Begin with the case in which the domestic firm charges $\bar{P}$ during $\left[t^{0}, t^{0}+\varepsilon\right]$. Since the quota is binding and consumer arbitrage takes place, the effect on the domestic firm's demand is exactly what it would be if the foreign firm charged some arbitrage price $p^{A}(\geq \hat{p}$ ). ${ }^{4}$ Thus, during the interval $\left[\mathrm{t}^{0}, \mathrm{t}^{0}+\varepsilon\right]$ the domestic firm makes the profit:

$$
\begin{aligned}
& \int_{\mathrm{t}^{0}}^{\mathrm{t}^{0}+\varepsilon} \mathrm{e}^{-\mathrm{r}\left(\mathrm{t}-\mathrm{t}^{0}\right)}\left\{\overline{\mathrm{P} X}\left(\overline{\mathrm{P}}, \mathrm{p}^{\mathrm{A}}\right)-\mathrm{C}\left[\mathrm{X}\left(\overline{\mathrm{P}}, \mathrm{p}^{\mathrm{A}}\right)\right]\right\} \mathrm{dt} \\
& \quad=\varepsilon\left\{\overline{\mathrm{PX}}\left(\overline{\mathrm{P}}, \mathrm{p}^{\mathrm{A}}\right)-\mathrm{C}\left(\mathrm{X}\left(\overline{\mathrm{P}}, \mathrm{p}^{\mathrm{A}}\right)\right)\right\},
\end{aligned}
$$

where we used the fact that for small $\varepsilon$

\footnotetext{
4 The actual value of $\mathrm{p}^{\mathrm{A}}$ is different from that in Section 2.
} 


$$
\int_{t}^{t+\varepsilon} f(z) d z=f(t) \varepsilon .
$$

Then, the foreign firm reaches the quantitative limit $\overline{\mathrm{q}}$ by the time $\mathrm{t}^{0}+\varepsilon$, and will make no more sales after that. This will allow the domestic firm to charge the monopoly price $\mathrm{P}^{\mathrm{m}}$ and earn the monopoly profit for the rest of the year.. Let $\Phi^{\mathrm{m}}\left(\mathrm{t}^{0}+\varepsilon\right)$ denote the discounted sum of the monopoly profits earned in the interval $\left[\mathrm{t}^{0}+\varepsilon, 1\right)$. Now, we can write the profit from charging $\overline{\mathrm{P}}$ as:

$$
\Omega\left(\overline{\mathrm{P}}, \hat{\mathrm{p}}, \mathrm{t}^{0}\right)=\varepsilon\left\{\overline{\mathrm{P} X}\left(\overline{\mathrm{P}}, \mathrm{p}^{\mathrm{A}}\right)-\mathrm{C}\left(\mathrm{X}\left(\overline{\mathrm{P}}, \mathrm{p}^{\mathrm{A}}\right)\right)\right\}+\Phi^{\mathrm{m}}\left(\mathrm{t}^{0}+\varepsilon\right)
$$

Consider next the case in which the domestic firm charges the low price $\underline{P}$ in $\left[t^{0}, t^{0}\right.$ $+\varepsilon]$. The domestic firm's profit during this short interval is given by

$$
\varepsilon\{\underline{P X}(\underline{P}, \hat{p})-C(X(\underline{P}, \hat{p}))\}
$$

In this case the foreign firm will not use up its quota by time $t^{0}+\varepsilon$ but continue to engage in duopolistic competition for some time after $\left(\mathrm{t}^{0}+\varepsilon\right)$. Let $\Phi\left(\mathrm{t}^{0}+\varepsilon\right)$ denote the discounted sum of the profits to the domestic firm in the interval $\left[\mathrm{t}^{0}+\varepsilon, 1\right)$. Then, the domestic firm's future profit is given by:

$$
\Omega\left(\underline{\mathrm{P}}, \hat{\mathrm{p}}, \mathrm{t}^{0}\right)=\varepsilon\{\underline{\mathrm{P} X}(\underline{\mathrm{P}}, \hat{\mathrm{p}})-\mathrm{C}(\mathrm{X}(\underline{\mathrm{P}}, \hat{\mathrm{p}}))\}+\Phi\left(\mathrm{t}^{0}+\varepsilon\right)
$$

Comparing the profits after $\mathrm{t}^{0}+\varepsilon$, we have that 


$$
\Phi\left(\mathrm{t}^{0}+\varepsilon\right)<\Phi^{\mathrm{m}}\left(\mathrm{t}^{0}+\varepsilon\right)
$$

since $\Phi^{\mathrm{m}}\left(\mathrm{t}^{0}+\varepsilon\right)$ sums up all the monopoly profits between $\mathrm{t}^{0}+\varepsilon$ and $1 . .^{5}$ Therefore, for $\varepsilon$ arbitrarily small, we have

$$
\Omega\left(\overline{\mathrm{P}}, \hat{\mathrm{p}}, \mathrm{t}^{0}\right)>\Omega\left(\underline{\mathrm{P}}, \hat{\mathrm{p}}, \mathrm{t}^{0}\right)
$$

implying that the domestic firm strictly prefers charging $\overline{\mathrm{P}}$ to charging $\underline{\mathrm{P}}$. But this

contradicts the initial hypothesis that the domestic firm randomizes between $\overline{\mathrm{P}}$ and $\underline{\mathrm{P}}$ in the interval $\left[\mathrm{t}^{0}, \mathrm{t}^{0}+\varepsilon\right]$. Since $\mathrm{t}^{0}$ is arbitrary, this contradiction proves that the domestic firm does not randomize at $\mathrm{t} \in[0,1){ }^{6}$

To complete the proof, we must show that the quota is not used up at $t<1$ in a purestrategy equilibrium, either. To see this, suppose the contrary; that is, suppose that the foreign firm makes the final sale of $\mathrm{x}$ units at $\mathrm{t}<1$. Should it postpone the sale of one unit of output to $t+\varepsilon$ instead, the foreign firm would lose $\mathrm{p}^{\prime}(\mathrm{x}) \mathrm{x}+\mathrm{p}(\mathrm{x})-\mathrm{c}^{\prime}(\mathrm{x})$ in profit at time $\mathrm{t}$ but would gain $\mathrm{p}(0)-\mathrm{c}^{\prime}(0)$ at time $\mathrm{t}+\varepsilon$. For an arbitrarily small $\varepsilon$, therefore, such postponement would always increase the foreign firm's intertemporal profit. The proof of Proposition 1 is now complete.

\footnotetext{
5 The difference between $\Phi^{\mathrm{m}}\left(\mathrm{t}^{0}+\varepsilon\right)$ and $\Phi\left(\mathrm{t}^{0}+\varepsilon\right)$ may be small if the quota is used up shortly after $\mathrm{t}^{0}+$ $\varepsilon$ or if the rates of exports are low. However small, the difference, $\Phi^{\mathrm{m}}\left(\mathrm{t}^{0}+\varepsilon\right)-\Phi\left(\mathrm{t}^{0}+\varepsilon\right)$, does not vanish when $\varepsilon$ goes to zero, which is sufficient to produce a desired contradiction.

6 This result is not affected by the size of $r(<\infty)$.
} 
As we already noted, a mixed-strategy equilibrium outcome emerges only at the moment when the quota is all used up. But Proposition 1 says that a mixed-strategy outcome is never observed at $\mathrm{t}<1$. These two results lead to the next proposition.

Proposition 2: In the equilibrium the foreign firm does not use up its quota before the end of the year. That is:

$$
\mu(\mathrm{t})<\overline{\mathrm{q}} \text { for all } \mathrm{t}<1
$$

and

$$
\lim _{t \rightarrow 1} \mu(t)=\bar{q}
$$

\section{Equilibrium paths under the quota}

Now we solve the model. Propositions 1 and 2 let us focus on a pure-strategy equilibrium. We use dynamic programming techniques to obtain a subgame-perfect equilibrium. ${ }^{7}$

Let $\widetilde{P}[t ; j, \mu(j)]$ and $\widetilde{p}[t ; j, \mu(j)]$ denote the equilibrium paths for the subgame starting at time $\mathrm{j}(<1)$ with the initial condition that the foreign firm has sold $\mu(\mathrm{j})(<\overline{\mathrm{q}})$ between $[0, j)$. Then the intertemporal equilibrium profits for this subgame are given by:

$$
\Pi[j, \mu(j)] \equiv \int_{j}^{1} e^{-r z}\{\widetilde{P} X(\widetilde{P}, \widetilde{p})-C(X(\widetilde{P}, \widetilde{p}))\} d z
$$

for the domestic firm and,

\footnotetext{
${ }^{7}$ See Kamien and Schwartz (1981, chapter 20) for an exposition of dynamic programming techniques.
} 


$$
\pi[j, \mu(j)] \equiv \int_{j}^{1} e^{-r z}\{\tilde{p} x(\widetilde{P}, \tilde{p})-c[x(\widetilde{P}, \widetilde{p})]\} d z
$$

for the foreign firm. Now divide the interval $[\mathrm{t}, 1)$ into two disjoint subintervals $[\mathrm{t}, \mathrm{t}+\Delta \mathrm{t}$ ) and $[\mathrm{t}+\Delta \mathrm{t}, 1)$, where $\Delta \mathrm{t}$ is small. Assume that the optimization problem is solved for the second subinterval, with the maximum profit from that subinterval denoted by $\Pi[\mathrm{t}+\Delta \mathrm{t}, \mu(\mathrm{t}$ $+\Delta \mathrm{t})]$. Then, by the principle of optimality we can express the domestic firm's optimization problem for the interval $[\mathrm{t}, 1)$ as:

$$
\begin{gathered}
\max _{P} \int_{\mathrm{t}}^{\mathrm{t}+\Delta \mathrm{t}} \mathrm{e}^{-\mathrm{rz}}\{\mathrm{P}(\mathrm{z}) \mathrm{X}(\mathrm{P}(\mathrm{z}), \mathrm{p}(\mathrm{z}))-\mathrm{C}(\mathrm{X}(\mathrm{P}(\mathrm{z}), \mathrm{p}(\mathrm{z}))) \mathrm{dz} \\
\quad+\Pi[\mathrm{t}+\Delta \mathrm{t}, \mu(\mathrm{t}+\Delta \mathrm{t})] .
\end{gathered}
$$

Note that $\mu(\mathrm{t}+\Delta \mathrm{t})=\mu(\mathrm{t})+\Delta \mu$. Since $\Delta \mathrm{t}$ is small, $\mathrm{P}(\mathrm{z})$ can be treated as a constant in (5). Also, for small $\Delta \mathrm{t}$ we have:

$$
\int_{t}^{t+\Delta t} f(z) d z=f(t) \Delta t .
$$

Using (6) on the first term of (5) and expanding the second term by a Taylor-series expansion, we can rewrite (5) as:

$$
\max _{P}\left\{\Delta t[P X(P, p)-C(X(P, p))] e^{-r t}\right.
$$




$$
\left.+\Pi(\mathrm{t}, \mu(\mathrm{t}))+\Pi_{\mathrm{t}}(\mathrm{t}, \mu(\mathrm{t})) \Delta \mathrm{t}+\Pi_{\mu}(\mathrm{t}, \mu(\mathrm{t})) \Delta \mu+\text { h.o.t. }\right\}
$$

where the h.o.t. represents all the higher-order terms in the Taylor-series expansion.

Since the second and the third term in (7) do not depend on P, they can be ignored in the optimization problem. Then, dividing through the remaining terms by $\Delta \mathrm{t}$ and taking the limit $\Delta \mathrm{t} \rightarrow 0$, we can rewrite the domestic firm's objective function as

$$
\max e^{-r t}[P X(P, p)-C(X(P, p))]+\Pi_{\mu}(t, \mu(t)) x(P, p)
$$

where $\mathrm{x}(\mathrm{P}, \mathrm{p})$ is used to replace $\mu^{\prime}(\mathrm{t}) .{ }^{8}$ The first-order condition to $(8)$ is given by

$$
\begin{gathered}
\Psi \equiv \mathrm{e}^{-\mathrm{rt}}\left\{\mathrm{X}(\mathrm{P}, \mathrm{p})+\mathrm{PX}_{\mathrm{P}}(\mathrm{P}, \mathrm{p})-\mathrm{C}^{\prime}(\mathrm{X}(\mathrm{P}, \mathrm{p})) \mathrm{X}_{\mathrm{P}}(\mathrm{P}, \mathrm{p})\right\} \\
+\Pi_{\mu}(\mathrm{t}, \mu(\mathrm{t})) \mathrm{x}_{\mathrm{P}}(\mathrm{P}, \mathrm{p})=0,
\end{gathered}
$$

which defines the domestic firm's best-response function $B(p, t)$ at time $t$.

The first-order condition (9) has the following interpretation. The first term measures the change in the domestic firm's profit at time t due to a small increase in P. Raising $\mathrm{P}$ also induces an instantaneous increase in imports $\left(\mathrm{x}_{\mathrm{P}}>0\right)$, which reduces the remaining quota through the increase in $\mu(\mathrm{t})$, which in turn raises the domestic firm's profits from sales made during the remainder of the year $\left(\Pi_{\mu}>0\right)$. This dynamic effect of a price change is captured in the second term on the right-hand side of (9). For an optimum the domestic firm chooses $\mathrm{P}$ to equate these two marginal effects on profits.

The properties of the best-response function $\mathrm{B}(\mathrm{p}, \mathrm{t})$ can now be examined. We first compare $B(p, t)$ with the best-response function $B^{S}(p)$ from the static game of Section 2 . Notice that the expression in braces in (9) is the same as the first-order condition of the 
static game [see eq. (2)]. The second term in (9) is positive by the preceding argument. Therefore, for a given $\mathrm{p}$ the domestic price $\mathrm{P}$ must be higher in the dynamic game than in the static game; i.e., $P(t)=B(p, t)>B^{s}(p)$. Graphically, $B(p, t)$ lies “outside" $B^{s}(p)$.

We next examine how the domestic firm's best-response function shifts over time. Differentiating (9), while holding p constant, we obtain

$$
\mathrm{dP} / \mathrm{dt}=-\frac{\left(\Pi_{\mu \mathrm{t}}+\Pi_{\mu \mu} \mathrm{x}\right) \mathrm{x}_{\mathrm{P}}+\mathrm{r} \Pi_{\mu} \mathrm{x}_{\mathrm{P}}}{\mathrm{e}^{-\mathrm{rt}}\left(2 \mathrm{X}_{\mathrm{P}}+\mathrm{PX} \mathrm{XP}_{\mathrm{PP}}-\mathrm{C}^{\prime \prime} \mathrm{X}_{\mathrm{P}}^{2}-\mathrm{C}^{\prime} \mathrm{X}_{\mathrm{PP}}\right)+\Pi_{\mu} \mathrm{x}_{\mathrm{PP}}} .
$$

The denominator is negative by the second-order condition. Lemma 1 in the Appendix shows that $\left(\Pi_{\mu \mathrm{t}}+\Pi_{\mu \mu} \mathrm{x}\right) \mathrm{x}_{\mathrm{P}}$ is positive. Since $\Pi_{\mu}$ and $\mathrm{x}_{\mathrm{P}}$ are also positive, we have $\mathrm{dP} / \mathrm{dt}>$ 0 , meaning that the domestic firm's best-response function shifts out over time. To sum the result so far, the domestic firm's dynamic best-response function under the quota is located outside of its static-game (and hence free-trade) best-response function, and shifts out over time.

Turning to the foreign firm, we write its optimization problem as

$$
\begin{gathered}
\max _{\mathrm{p}} \int_{\mathrm{t}}^{\mathrm{t}+\Delta \mathrm{t}} \mathrm{e}^{-\mathrm{rz}}\{\mathrm{p}(\mathrm{z}) \mathrm{x}(\mathrm{P}(\mathrm{z}), \mathrm{p}(\mathrm{z}))-\mathrm{c}(\mathrm{x}(\mathrm{P}(\mathrm{z}), \mathrm{p}(\mathrm{z}))\} \mathrm{dz} \\
\quad+\pi(\mathrm{t}+\Delta \mathrm{t}, \mu(\mathrm{t}+\Delta \mathrm{t})) .{ }^{9}
\end{gathered}
$$

The procedure used in the case of the domestic firm can be applied to simplify (11) to the following problem:

$$
\max _{\mathrm{p}} \mathrm{e}^{-\mathrm{rt}}\{\mathrm{px}(\mathrm{P}, \mathrm{p})-\mathrm{c}(\mathrm{x}(\mathrm{P}, \mathrm{p}))\}+\pi_{\mu}(\mathrm{t}, \mu(\mathrm{t})) \mathrm{x}(\mathrm{P}, \mathrm{p})
$$

\footnotetext{
${ }^{8}$ By definition, $\mu^{\prime}(t)=x(P, p)$. Note also that the h.o.t. vanishes when the limit is taken.
} 
The first-order condition is

$$
\begin{aligned}
\psi \equiv \mathrm{e}^{-\mathrm{rt}}\left\{\mathrm{x}(\mathrm{P}, \mathrm{p})+\mathrm{px}_{\mathrm{p}}(\mathrm{P}, \mathrm{p})-\mathrm{c}^{\prime}(\mathrm{x}(\mathrm{P}, \mathrm{p})) \mathrm{x}_{\mathrm{p}}(\mathrm{P}, \mathrm{p})\right\} \\
+\pi_{\mu}(\mathrm{t}, \mu(\mathrm{t})) \mathrm{x}_{\mathrm{p}}(\mathrm{P}, \mathrm{p})=0,
\end{aligned}
$$

which yields the foreign firm's best-response function, $p=b(P, t)$, at time $t<1$.

How does $b(P, t)$ compare with the best-response function $b^{\mathrm{s}}(\mathrm{P})$ from the one-shot game in Section 2? The expression in braces in (12) is the same as that in the first-order condition in the static game [see eq. (1)], so the position of $b(P, t)$ relative to $b^{s}(P)$ depends on the second term in (12), which captures the following dynamic effect. A small increase in $\mathrm{p}$ decreases the demand for exports $\left(\mathrm{x}_{\mathrm{p}}<0\right)$, thereby relaxing the quota constraint for the remainder of the year and affecting the foreign firm's future profit by $\pi_{\mu}$.

Thus the term $\left(-\pi_{\mu}\right)$ may be interpreted as the dynamic shadow price of the quota. ${ }^{10}$ This shadow price is positive (i.e., $\pi_{\mu}<0$ ) when the quota is binding. The intuition is that when $\mu$ increases the foreign firm has less to export for the rest of year and hence earns a smaller profit. Formally, suppose contrarily that $\pi_{\mu} \geq 0$, implying that the foreign firm's equilibrium profit is increased by a decrease in the (remaining) quota. Then, the foreign firm would voluntarily give up a portion of the quota until $\pi_{\mu}$ becomes negative. In the absence of such an option, the foreign firm would export in an instant whatever quantity is needed to make $\pi_{\mu}$ negative. While such an action may yield a negative profit instantaneously, its

\footnotetext{
${ }^{9}$ By definition $\pi$ is the equilibrium profit under the quota, so it subsumes the quota constraint (4).

${ }^{10}$ See Kamien and Schwartz (1981, p. 240) for this interpretation.
} 
effect on total profit is of measure zero and is overwhelmed by an increase in profits due to a smaller quota that it now faces.

Given that $\pi_{\mu}<0$, the second term on the right-hand side of (12) is positive, implying that $\mathrm{p}=\mathrm{b}(\mathrm{P}, \mathrm{t})>\mathrm{b}^{\mathrm{S}}(\mathrm{P})$; that is, for a given $\mathrm{P}$, the domestic firm charges a higher price than it does in a static game.

We next examine the transition of the foreign firm's best-response function over time. Differentiating (12), while holding P constant, yields:

$$
\mathrm{dp} / \mathrm{dt}=-\frac{\left(\pi_{\mu t}+\pi_{\mu \mu} \mathrm{x}\right) \mathrm{x}_{\mathrm{p}}+\mathrm{r} \pi_{\mu} \mathrm{x}_{\mathrm{p}}}{\mathrm{e}^{-\mathrm{rt}}\left(2 \mathrm{x}_{\mathrm{p}}+\mathrm{p} \mathrm{x}_{\mathrm{pp}}-\mathrm{c}^{\prime \prime} \mathrm{x}_{\mathrm{p}}{ }^{2}-\mathrm{c}^{\prime} \mathrm{x}_{\mathrm{pp}}\right)+\pi_{\mu} \mathrm{x}_{\mathrm{pp}}} .
$$

The denominator is negative by the second-order condition. Lemma 2 in the appendix shows that the first term of the numerator is positive. Thus, the direction of shift again depends on the sign of $\pi_{\mu}$. Since $\pi_{\mu}$ is negative, $\mathrm{dp} / \mathrm{dt}>0$, so the foreign firm's bestresponse function shifts out over time.

Solving the best-response functions (9) and (12) simultaneously, we can find the equilibrium prices at each $\mathrm{t}$. Let $\mathrm{P}^{*}(\mathrm{t})$ and $\mathrm{p}^{*}(\mathrm{t})$ denote the equilibrium outcome for the whole game; that is, $\mathrm{P}^{*}(\mathrm{t}) \equiv \widetilde{\mathrm{P}}[\mathrm{t} ; 0, \mu(0)]$ and $\mathrm{p}^{*}(\mathrm{t}) \equiv \widetilde{\mathrm{p}}[\mathrm{t} ; 0, \mu(0)]$ for $\mathrm{t} \in[0,1)$.

We now present some properties of the equilibrium price paths. We already established that under the quota the domestic firm's best-response function is located outside its static-game counterpart, $\mathrm{B}^{\mathrm{S}}(\mathrm{p})$, and shifts out over time. We then proved that the foreign firm's best-response function also is placed on or outside the best-response function $\mathrm{b}^{\mathrm{s}}(\mathrm{P})$ and shifts out after some $\mathrm{t} \geq 0$. These facts lead to the following general result. 
Proposition 3: The prices under the quota are higher than what they are under free trade and increasing over time:

$$
\mathrm{P}^{*}(\mathrm{t})>\mathrm{P}^{\mathrm{s}}(\mathrm{t}), \mathrm{p}^{*}(\mathrm{t})>\mathrm{p}^{\mathrm{s}}(\mathrm{t}), \mathrm{P}^{*}{ }^{\prime}(\mathrm{t})>0 \text {, and } \mathrm{p}^{* \prime}(\mathrm{t})>0 \text { for } \mathrm{t} \in[0,1) \text {. }
$$

We now ask what happens when the home government imposes a more restrictive quota. A tighter quota raises the shadow price of the quota at each point in time, thereby inducing the foreign firm to raise its price at $\mathrm{t} \in[0,1)$. Further, since prices are strategic complements, the domestic price also rises throughout the period. We state this in the next proposition, while relegating the proof to the appendix (see lemma 3 ).

Proposition 4: Decreasing the quota raises both firms' price trajectories.

\section{Quotas as facilitating practices}

Krishna (1989) showed for a one-shot differentiated-good Bertrand game that both the foreign and the home firm earn greater profits under a quota than under free trade. This result holds when there is a tariff; i.e., a quota results in a more collusive equilibrium than the equal-import tariff. In this section we examine whether this property extends to the dynamic setting we consider.

As before, focus on the interval $[0,1)$, and set the quota equal to the quantity of imports under free trade:

$$
\overline{\mathrm{q}}^{\mathrm{f}}=\int_{0}^{1} \mathrm{x}\left(\mathrm{P}^{\mathrm{s}}, \mathrm{p}^{\mathrm{s}}\right) \mathrm{dt} .
$$


The free-trade prices $\mathrm{P}^{\mathrm{s}}$ and $\mathrm{p}^{\mathrm{s}}$ obviously meet the constraint (13). They fail to satisfy the first-order conditions (9) and (12), however, and hence no longer constitute a subgameperfect equilibrium. ${ }^{11}$ Thus, the imposition of the quota at the free-trade level of imports affects the equilibrium behavior in our model.

Our analysis of section 4 is fully applicable here. Thus, under the quota the domestic firm's best-response function is located outside its free-trade position and shifts out over time. The foreign firm's best-response function also behaves similarly although it may be identical to its static counterpart momentarily. With both the best-response functions being displaced outward from their respective free-trade positions, the equilibrium prices are higher under the quota than under free trade. Thus, $\mathrm{P}^{* \mathrm{f}}(\mathrm{t})>\mathrm{P}^{\mathrm{s}}$ and $\mathrm{p} * \mathrm{f}(\mathrm{t})>\mathrm{p}^{\mathrm{s}}$ for all $\mathrm{t} \in[0,1)$. Then, both firms' profits are greater under the quota $\overline{\mathrm{q}}^{\mathrm{f}}$ than under free trade. By an extension, the foreign firm earns a greater profit under a quota than under the equalimport tariff even if the tariff revenue were returned to the foreign firm. In other words, a quota facilitates collusion relative to the equal-import tariff, .

Proposition 5. Both the foreign firm and the domestic firm earn greater profits under a quota than they do under the equal-import tariff.

\section{Concluding remarks}

This paper explores the fundamental difference between the capacity-constrained firm and the quota-constrained firm. Quotas limit the total quantity the foreign firm is allowed to export within a given period, say, a year. As a consequence the firm under the

\footnotetext{
11 To see this, suppose that firms charge $\mathrm{P}^{\mathrm{S}}, \mathrm{p}^{\mathrm{s}}$ at time zero (the moment the quota is imposed). Then the first expression on the right-hand side of (9) vanishes. Since $\Pi_{\mu}[0, \mu(0)] x_{P}>0$ the first-order condition (9)
} 
quota can strategically vary rates of export at every instant as long as the sum of exports does not exceed the quota. In contrast, capacity constraints are more physical, limiting the firm's production ability per unit of time, say, due to the plant size. As a result, the capacityconstrained firm does not face the isoperimetric problem as the firm does under the quota. This difference is obscured in the literature examining the relative effect of quota, which analyzes firms under a quota as capacity-constrained ones.

One benefit from treating the quota as an isoperimetric problem is that firms play pure strategies at all times. This fact is helpful in solving the dynamic profit-maximization problems under the quota. We develop techniques to solve this type of differential games, and fully characterize the equilibrium path for the quota-constrained Bertrand duopoly model, the one-shot version of which was considered in Krishna (1989).

We show that the quota results in higher and increasing prices than the tariff of equal imports. Our result also shows that price variations are greater under the quota as prices increase over time. Further, if the annual quota is renewed every year, the saw-toothed price trajectories appear every year: the quota produces price and output cycles while they are stationary under the tariff.

The techniques we developed are useful in analyzing other models of one-shot games under the quota that have mixed-strategy equilibriums, e.g., Reitzes and Grawe (1994). We leave such applications of the present analysis to future work.

is not satisfied. 
Appendix: Proofs of the three lemmas mentioned in the text are presented.

Lemma 1. $\left(\Pi_{\mu \mathrm{t}}+\Pi_{\mu \mu} \mathrm{x}\right) \mathrm{x}_{\mathrm{P}}>0$

Proof: First, since goods are substitutes, we have $\mathrm{x}_{\mathrm{P}}>0$. Therefore, the proof is complete if we show $\Pi_{\mu \mathrm{t}}+\Pi_{\mu \mu} \mathrm{x}>0$. The definition of the maximum profit function and the principle of optimality imply

$$
\begin{aligned}
\Pi[\mathrm{t}, \mu(\mathrm{t})] & \equiv \Delta \mathrm{t}\{\widetilde{\mathrm{P} X}(\widetilde{\mathrm{P}}, \widetilde{\mathrm{p}})-\mathrm{C}(\mathrm{X}(\widetilde{\mathrm{P}}, \widetilde{\mathrm{p}}))\} \mathrm{e}^{-\mathrm{rt}}+\Pi[\mathrm{t}+\Delta \mathrm{t}, \mu(\mathrm{t})+\Delta \mu] \\
= & \Delta \mathrm{t}\{\widetilde{\mathrm{P} X}(\widetilde{\mathrm{P}}, \widetilde{\mathrm{p}})-\mathrm{C}(\mathrm{X}(\widetilde{\mathrm{P}}, \widetilde{\mathrm{p}}))\} \mathrm{e}^{-\mathrm{rt}} \\
+ & \left\{\Pi[\mathrm{t}, \mu(\mathrm{t})]+\Pi_{\mathrm{t}}[\mathrm{t}, \mu(\mathrm{t})] \Delta \mathrm{t}+\Pi_{\mu}[\mathrm{t}, \mu(\mathrm{t})] \Delta \mu+\text { h.o.t. }\right\}
\end{aligned}
$$

where the equality follows from a Taylor series expansion. Dividing through by $\Delta \mathrm{t}$ and taking the limit $\Delta \mathrm{t} \rightarrow 0$ yields the Bellman equation:

$$
-\Pi_{\mathrm{t}}[\mathrm{t}, \mu(\mathrm{t})]=\mathrm{e}^{-\mathrm{rt}}\{\widetilde{\mathrm{P} X}(\widetilde{\mathrm{P}}, \tilde{\mathrm{p}})-\mathrm{C}(\mathrm{X}(\widetilde{\mathrm{P}}, \tilde{\mathrm{p}}))\}+\Pi_{\mu}[\mathrm{t}, \mu(\mathrm{t})] \mathrm{x}(\widetilde{\mathrm{P}}, \widetilde{\mathrm{p}}) .
$$

Since this holds for all $\mu$, we can differentiate (A1) with respect to $\mu$ to obtain:

$$
\begin{aligned}
& -\Pi_{t \mu}[\mathrm{t}, \mu(\mathrm{t})]=\mathrm{e}^{-\mathrm{rt}}\left\{\widetilde{\mathrm{P}} \mathrm{X}_{\mathrm{p}}(\widetilde{\mathrm{P}}, \tilde{\mathrm{p}})-\mathrm{C}^{\prime}(\mathrm{X}(\widetilde{\mathrm{P}}, \widetilde{\mathrm{p}})) \mathrm{X}_{\mathrm{p}}\right\} \widetilde{\mathrm{p}}_{\mu} \\
& +\Pi_{\mu \mu}[\mathrm{t}, \mu(\mathrm{t})] \mathrm{x}(\widetilde{\mathrm{P}}, \tilde{\mathrm{p}})+\Pi_{\mu}[\mathrm{t}, \mu(\mathrm{t})] \mathrm{x}_{\mathrm{p}}(\widetilde{\mathrm{P}}, \widetilde{\mathrm{p}}) \tilde{\mathrm{p}}_{\mu},
\end{aligned}
$$

which simplifies to

$$
\begin{aligned}
& \Pi_{\mu \mu}[\mathrm{t}, \mu(\mathrm{t})] \mathrm{x}(\widetilde{\mathrm{P}}, \tilde{\mathrm{p}})+\Pi_{\mathrm{t} \mu}[\mathrm{t}, \mu(\mathrm{t})] \\
& \quad=-\left\{\mathrm{e}^{-\mathrm{rt}}\left\{\widetilde{\mathrm{P}} \mathrm{X}_{\mathrm{p}}(\widetilde{\mathrm{P}}, \widetilde{\mathrm{p}})-\mathrm{C}^{\prime}(\mathrm{X}(\widetilde{\mathrm{P}}, \widetilde{\mathrm{p}})) \mathrm{X}_{\mathrm{p}}\right\}+\Pi_{\mu}[\mathrm{t}, \mu(\mathrm{t})] \mathrm{x}_{\mathrm{p}}(\widetilde{\mathrm{P}}, \widetilde{\mathrm{p}})\right\} \widetilde{\mathrm{p}}_{\mu} \cdot
\end{aligned}
$$

Rearranging the first-order condition (9) yields 


$$
\begin{aligned}
& \mathrm{e}^{-\mathrm{rt}}\left\{\widetilde{\mathrm{P}} \mathrm{X}_{\mathrm{P}}(\widetilde{\mathrm{P}}, \tilde{\mathrm{p}})-\mathrm{C}^{\prime}(\mathrm{X}(\widetilde{\mathrm{P}}, \tilde{\mathrm{p}})) \mathrm{X}_{\mathrm{P}}(\widetilde{\mathrm{P}}, \tilde{\mathrm{p}})\right\} \\
& \quad=-\Pi_{\mu}[\mathrm{t}, \mu(\mathrm{t})] \mathrm{x}_{\mathrm{P}}(\widetilde{\mathrm{P}}, \tilde{\mathrm{p}})-\mathrm{e}^{-\mathrm{rt}} \mathrm{X}(\widetilde{\mathrm{P}}, \tilde{\mathrm{p}}) .
\end{aligned}
$$

Substituting this expression, we can express the right-hand side of (A2) as

$$
-\left\{-\mathrm{e}^{-\mathrm{rt}} \mathrm{X}(\mathrm{P}, \mathrm{p})+\Pi_{\mu}[\mathrm{t}, \mu(\mathrm{t})]\left[\mathrm{x}_{\mathrm{p}}(\widetilde{\mathrm{P}}, \widetilde{\mathrm{p}})-\mathrm{x}_{\mathrm{P}}(\widetilde{\mathrm{P}}, \widetilde{\mathrm{p}})\right]\right\} \widetilde{\mathrm{p}}_{\mu}
$$

Since we have $\Pi_{\mu}>0$, the terms in the braces are negative. Also, in Lemma 3 below, we show $\widetilde{\mathrm{p}}_{\mu}>0$. Therefore, we have $\Pi_{\mu \mu} \mathrm{x}+\Pi_{\mathrm{t} \mu}>0$.

Lemma 2. $\left(\pi_{\mu \mathrm{t}}+\pi_{\mu \mu} \mathrm{x}\right) \mathrm{x}_{\mathrm{p}}>0$

Proof: Following a procedure similar to the one leading to (A1) in the proof of Lemma 1, we can obtain the Bellman equation for the foreign firm:

$$
-\pi_{\mathrm{t}}[\mathrm{t}, \mu(\mathrm{t})]=\mathrm{e}^{-\mathrm{rt}}\{\tilde{\mathrm{p}} \mathrm{x}(\widetilde{\mathrm{P}}, \widetilde{\mathrm{p}})-\mathrm{c}(\mathrm{x}(\widetilde{\mathrm{P}}, \tilde{\mathrm{p}}))\}+\pi_{\mu}[\mathrm{t}, \mu(\mathrm{t})] \mathrm{x}(\widetilde{\mathrm{P}}, \widetilde{\mathrm{p}}) .
$$

Differentiating (A3) with respect to $\mu$ yields:

$$
\begin{aligned}
& -\pi_{t \mu}[\mathrm{t}, \mu(\mathrm{t})]=\mathrm{e}^{-\mathrm{rt}}\left\{\widetilde{\mathrm{p}}-\mathrm{c}^{\prime}(\mathrm{x}(\widetilde{\mathrm{P}}, \widetilde{\mathrm{p}}))\right\} \mathrm{x}_{\mathrm{P}}(\widetilde{\mathrm{P}}, \widetilde{\mathrm{p}}) \widetilde{\mathrm{P}} \\
& \\
& +\pi_{\mu \mu}[\mathrm{t}, \mu(\mathrm{t})] \mathrm{x}(\widetilde{\mathrm{P}}, \widetilde{\mathrm{p}})+\pi_{\mu}[\mathrm{t}, \mu(\mathrm{t})] \mathrm{x}_{\mathrm{P}}(\widetilde{\mathrm{P}}, \widetilde{\mathrm{p}}) \widetilde{\mathrm{P}}_{\mu}
\end{aligned}
$$

or

$$
\begin{aligned}
& \pi_{t \mu}[\mathrm{t}, \mu(\mathrm{t})]+\pi_{\mu \mu}[\mathrm{t}, \mu(\mathrm{t})] \mathrm{x}(\widetilde{\mathrm{P}}, \widetilde{\mathrm{p}}) \\
& =-\left\{\mathrm{e}^{-\mathrm{rt}}\left\{\tilde{\mathrm{p}}-\mathrm{c}^{\prime}(\mathrm{x}(\widetilde{\mathrm{P}}, \widetilde{\mathrm{p}}))\right\}+\pi_{\mu}[\mathrm{t}, \mu(\mathrm{t})]\right\} \mathrm{x}_{\mathrm{P}}(\widetilde{\mathrm{P}}, \widetilde{\mathrm{p}}) \widetilde{\mathrm{P}}_{\mu} .
\end{aligned}
$$

The expression in braces on the right-hand side of (A4) is positive since rewriting the firstorder condition (12) from the text yields: 


$$
\mathrm{e}^{-\mathrm{rt}}\left\{\tilde{\mathrm{p}}-\mathrm{c}^{\prime}(\mathrm{x}(\widetilde{\mathrm{P}}, \tilde{\mathrm{p}}))\right\}+\pi_{\mu}[\mathrm{t}, \mu(\mathrm{t})]=-\mathrm{e}^{-\mathrm{rt}} \mathrm{x}(\widetilde{\mathrm{P}}, \tilde{\mathrm{p}}) / \mathrm{x}_{\mathrm{p}}(\widetilde{\mathrm{P}}, \tilde{\mathrm{p}})>0
$$

Furthermore, $\mathrm{x}_{\mathrm{P}}>0$ because products are substitutes, and $\widetilde{\mathrm{P}}_{\mu}>0$ as we prove later in Lemma 3. We have shown that the right-hand side of (A4) is negative. Lemma 2 then follows immediately from the fact that $\mathrm{x}_{\mathrm{p}}<0$.

Lemma 3. $\widetilde{\mathrm{p}}_{\mu}>0$ and $\widetilde{\mathrm{P}}_{\mu}>0$.

Proof: Differentiating the first-order conditions (9) and (12) simultaneously yields

$$
\begin{aligned}
& |\mathrm{D}| \mathrm{dP} / \mathrm{d} \mu=-\Pi_{\mu \mu} \mathrm{x}_{\mathrm{P}} \psi_{\mathrm{p}}+\pi_{\mu \mu} \mathrm{x}_{\mathrm{p}} \Psi_{\mathrm{p}} \\
& |\mathrm{D}| \mathrm{dp} / \mathrm{d} \mu=\Pi_{\mu \mu} \mathrm{x}_{\mathrm{P}} \psi_{\mathrm{P}}-\pi_{\mu \mu} \mathrm{x}_{\mathrm{p}} \Psi_{\mathrm{P}}
\end{aligned}
$$

where $|\mathrm{D}| \equiv \psi_{\mathrm{p}} \Psi_{\mathrm{P}}-\psi_{\mathrm{P}} \Psi_{\mathrm{p}}>0$ by the standard stability and uniqueness conditions. We also know that $\Psi_{\mathrm{P}}<0, \Psi_{\mathrm{p}}<0$ by the second-order conditions, and $\Psi_{\mathrm{p}}>0, \psi_{\mathrm{P}}>0$ due to strategic complementarity of prices.

We first show that $\pi_{\mu \mu}<0$. To do so, note that

$$
\begin{aligned}
& \pi\left(\mathrm{t}, \mu_{0}\right) \\
& >\pi\left(\mathrm{t}, \mu_{1}\right)+\left(\mu_{1}-\mu_{0}\right) \mathrm{e}^{-\mathrm{rt}}\left(\mathrm{x}+\mathrm{px}_{\mathrm{p}}-\mathrm{c}^{\prime} \mathrm{x}_{\mathrm{p}}\right) / \mathrm{x}_{\mathrm{p}} \\
& =\pi\left(\mathrm{t}, \mu_{1}\right)-\left(\mu_{1}-\mu_{0}\right) \pi_{\mu}\left(\mathrm{t}, \mu_{0}\right)
\end{aligned}
$$

for given $t, \mu_{1}$, and $\mu_{0}\left(\mu_{1}>\mu_{0}\right)$. The inequality holds for the following reason. Both sides of the inequality measure profits the foreign firm makes by exporting the quantity $\bar{q}-\mu_{0}$ between time $t$ and 1 . The left-hand side, $\pi\left(t, \mu_{0}\right)$, is by definition the foreign firm's 
maximum profit attainable. The first term, $\pi\left(t, \mu_{1}\right)$, on the right-hand side of the inequality is the maximum profit attainable by exporting the smaller quantity $\bar{q}-\mu_{1}$ during this period. The next term represents the profit resulting from exporting the quantity, $\mu_{1}-\mu_{0}$, at $\mathrm{e}^{-\mathrm{rt}}$ (x $\left.+\mathrm{px}_{\mathrm{p}}-\mathrm{c}^{\prime} \mathrm{x}_{\mathrm{p}}\right)$. However, since this term is not the maximum profit to the foreign firm from exporting $\mu_{1}-\mu_{0}$ units, the inequality is established. The equality in (A6) follows from the first-order condition (12). But (A6) means that $\pi(t, \mu)$ is concave in $\mu$ : that is, $\pi_{\mu \mu}<0$.

We next show that $\Pi_{\mu \mu}>0$. Let $\mu_{1}$ and $\mu_{0}$ be given, with $\mu_{1}>\mu_{0} . \Pi\left(\mathrm{t}, \mu_{1}\right)$ represents the maximum profit the domestic firm can make when $\bar{q}-\mu_{1}$ units of the foreign good are imported between $t$ and 1 . If $\bar{q}-\mu_{0}$ units were allowed to be imported instead during the same period, the domestic firm would suffer the loss $\Pi\left(\mathrm{t}, \mu_{1}\right)-\Pi\left(\mathrm{t}, \mu_{0}\right)>0$. Now suppose that the domestic firm receives a compensation for this loss in the amount of

$$
-e^{-r t}\left(X+P X_{P}-C^{\prime} X_{P}\right)\left(\mu_{1}-\mu_{0}\right) / x_{P}
$$

This has the following interpretation. Since $\mathrm{x}_{\mathrm{P}}$ measures the increase in imports induced by a unit increase in the domestic price, $\left(\mu_{1}-\mu_{0}\right) / x_{P}$ represents the price increase necessary to induce the increase in imports by $\mu_{1}-\mu_{0}$. But according to the first-order condition (9), the marginal cost of a price increase (a deviation from optimality) is

$$
-e^{-r t}\left(X+P X_{P}-C^{\prime} X_{P}\right)
$$


However, since the profit function is concave, this compensation evaluated at the margin underestimates the true cost of the discrete price change necessary to induce the increase in imports, $\mu_{1}-\mu_{0}$. Therefore,

$$
\begin{aligned}
\Pi\left(\mathrm{t}, \mu_{1}\right) & -\Pi\left(\mathrm{t}, \mu_{0}\right)>-\left(\mu_{1}-\mu_{0}\right) \mathrm{e}^{-\mathrm{rt}}\left(\mathrm{X}+\mathrm{PX}_{\mathrm{P}}-\mathrm{C}^{\prime} \mathrm{X}_{\mathrm{P}}\right) / \mathrm{x}_{\mathrm{P}} \\
& =\left(\mu_{1}-\mu_{0}\right) \Pi_{\mu}\left(\mathrm{t}, \mu_{0}\right),
\end{aligned}
$$

where the equality follows from (9). However, this means that $\Pi(t, \mu)$ is convex in $\mu$, and hence $\Pi_{\mu \mu}>0$. Using these results in (A5), we have $\widetilde{\mathrm{p}}_{\mu}>0$ and $\widetilde{\mathrm{P}}_{\mu}>0$. 


\section{References}

Brander, J.A., 1995, Strategic trade policy, in G.M. Grossman and K. Rogoff, eds., Handbook of international economics, volume 3 (North-Holland, Amsterdam).

Dockner, E.J., and A. A. Haug, 1990, Tariffs and quotas under dynamic duopolistic competition, Journal of International Economics 29, 147-160.

Itoh, M., and Ono, Y., 1982, Tariffs, quotas, and market structure, Quarter Journal of Economics 97, 295-305.

Itoh, M, and Y. Ono, 1984, Tariffs vs. quotas under duopoly of heterogeneous goods, Journal of International Economics 17, 359-374.

Harris, R., 1985, Why voluntary export restraints are 'voluntary', Canadian Journal of Economics 18, 799-809.

Helpman, E, and P. R. Krugman, 1989, Trade policy and market structure (MIT Press, Cambridge).

Hwang, H., and C. Mai, 1988, On the equivalence of tariffs and quotas under duopoly: a conjectural variation approach, Journal of International Economics 24, 373-380.

Kamien, M.I. and N.L. Schwartz, 1981. Dynamic optimization: the calculus of variations and optimal control in economics and management (North-Holland, Amsterdam)

Kreps, D. M., and J. A. Sheinkman, 1983. Quantity precommitment and Bertrand competition yield Cournot outcomes, Bell Journal of Economics 14, 326-337.

Krishna, K., 1989. Trade restrictions as facilitating practices, Journal of International Economics 26, 251-270.

Miyagiwa, K., and Y. Ohno, 1995. Closing the technology gap under protection, American Economic Review 85, 755-770.

Miyagiwa, K., and Y. Ohno, 1999. Credibility of protection and incentives to innovate, International economic Review 40, 143-164 
Miyagiwa, K., and Y. Ohno, 2001. Quota-induced cycles, International Economic Review $42,451-472$.

Reitzes, J. D., and O.R. Grawe, 1994. Market-share quotas, Journal of International Economics 36, 431-447.

Rotemberg, J., and G. Saloner, 1989, Tariffs vs. quotas with implicit collusion, Canadian Journal of Economics 22, 237-244. 
29

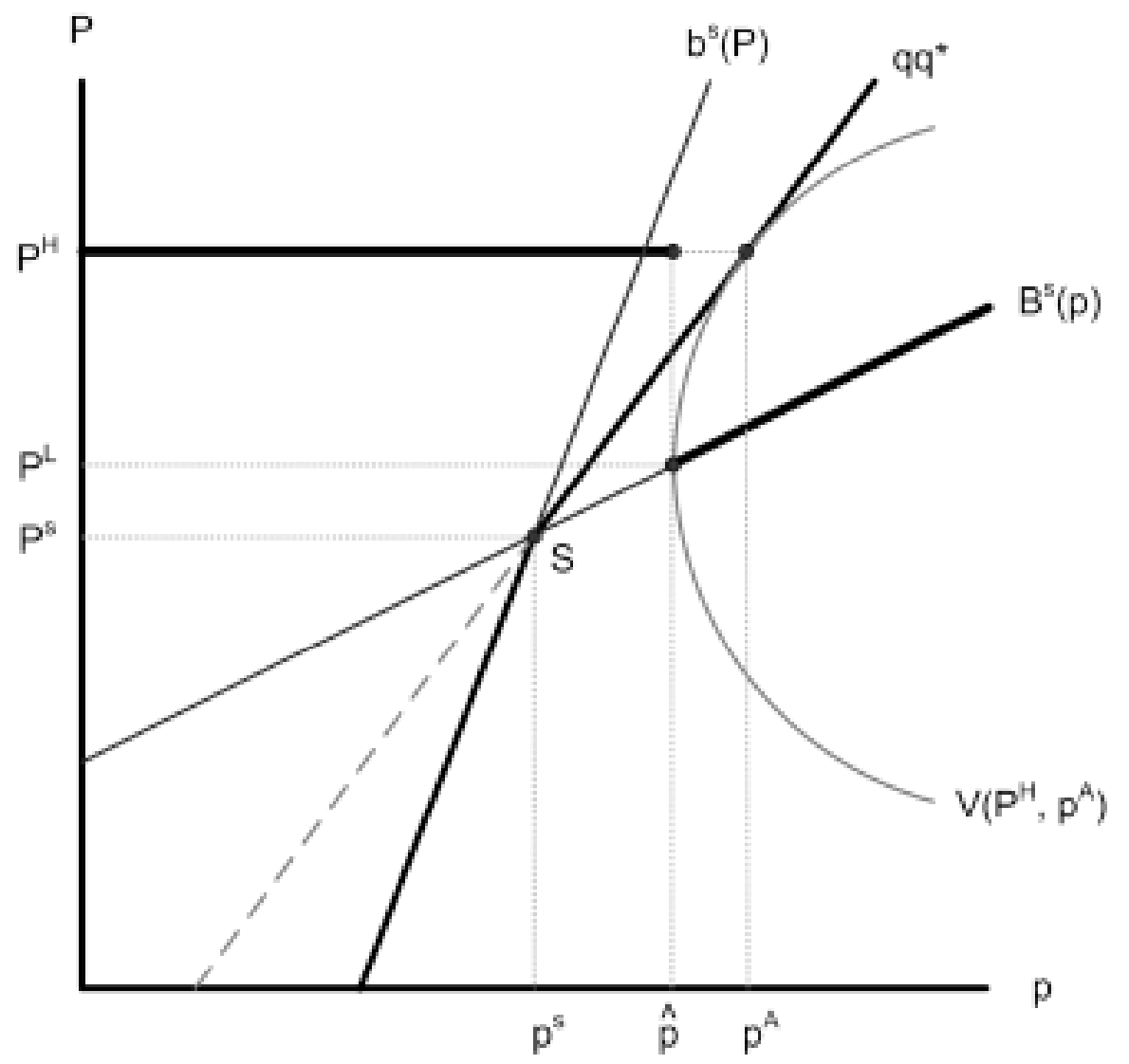

